\title{
Recovery of Copper and Cyanide from Copper-cyanide Solution by Direct Electrolysis
}

\author{
GAO Teng-yue ${ }^{1, *}, \mathrm{Xu}_{\mathrm{Chao}}{ }^{1}$, and QIN Guang-lin ${ }^{1}$ \\ ${ }^{1}$ Metallurgical laboratory branch of Shandong gold mining technology Co., Led., 261400 Yantai, China
}

\begin{abstract}
Using direct electrolysis method, the recovery of copper and cyanide from high concentration copper cyanide solution was researched. The distribution of copper cyanide species was calculated by stability constants and balance equation. The results showed that the cupric ion was confirmed to generate at low potential $(<0.4 \mathrm{~V})$ on the titanium electrode coated with iridium and tantalum oxides during the electrolysis process, which led to the oxidation of cyanide and the precipitate obtained on the anode was proved to be cupric hydroxide by XRD at high potential. The copper was recovered by direct electrowinning, the recovery of copper increased with increasing temperature, which reached $80 \%$ at $70^{\circ} \mathrm{C}$; but the loss of cyanide was serious, the free cyanide concentration was significantly lower than original value.
\end{abstract}

\section{Introduction}

The cyanide is the most widely applied leaching reagent for gold minerals due to its high efficiency and low cost. However, as a common paragenetic element, amounts of copper can be dissolved during the cyanidation process, which significantly increased the consumption of cyanide. Furthermore, part of the dissolved copper ions became insoluble copper cyanide complexes and coated on the surface of gold-bearing minerals, which decreased the cyanide leaching speed. Since the cyanide solution containing copper can't be directly recovered for leaching, the separation-recovery of copper and cyanide respectively in the barren solution is the key point to solve the problem [1]. AVR (acidification, volatilization and regeneration) technique and some modifications thereof [2-3] have been widely used to treat the solution in the gold industry, but there is a hidden serious danger because the highly toxic of hydrocyanic acid produced in this process, while copper is recovered as complexingprecipitate which should be treated further to obtain metal and the natural degradation of residual cyanide in wastewater is necessary. Solvent extraction [4-5] before AVR has been investigated to recover copper and cyanide, the copper cyanide complexes can be effectively extracted and concentrated into higher concentration for further recovery; however, the high concentration copper cyanide solution is still treated by traditional method, therefore, the same danger still exists.

Direct electrowinning has been researched for a long time and considered to be a potential technique for recovery of copper and cyanide. Since the cyanide would be destroyed in electrowinning process [6], the membrane was chose to avoid cyanide oxidation on anode [7-8]. However, the expensive price and short lifetime of membrane seriously restrain its industrial application. Furthermore, most work [9-11] has been focused on direct electrowinning of dilute copper cyanide solution whose current efficiency is low. It has been demonstrated that the copper can catalyze cyanide decompose; However, the reaction mechanism of copper cyanide oxidation on anode are incomplete [12-14]. On the other hand, less investigation has been carried on the high concentration copper cyanide solution at present. It is obvious advantage that electrodepositon of concentrated solution because the current efficiency is greatly improved. It is necessary to pay attention to the oxidation of cyanide on anode, which is the key to achieve direct electrowinning concentrated copper cyanide solution.

In this work, direct electrowinning of high concentration copper cyanide solution was carried out to recover copper and cyanide. The distributions of copper cyanide species were calculated by stability constants at different temperatures and $\mathrm{pH}$ [15]. Cyclic voltammetry behaviors of copper cyanide complex were discussed on different electrodes. Correspondingly, the electrochemical reactions in this process were proposed.

\section{Experimental}

All solutions were prepared by analytical grade reagents and deionized water. The $\mathrm{CuCN}$ was dissolved into $\mathrm{NaOH}+\mathrm{NaCN}$ solution and adding $\mathrm{Na}_{2} \mathrm{SO}_{4}$ to make the final solution. The free cyanide concentration was measured using titration with silver nitrate, potassium iodide as indicator. The copper concentration of copper cyanide solution was analyzed by atomic absorption spectrometry (AAS). The current efficiency of cathode

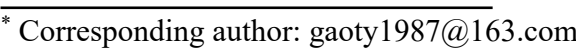


was determined by the initial and final concentration in the solution.

Copper cyanide dissolved into cyanide solution to form cyanocuprate ions, the concentration distributions are dependent on $\mathrm{pH}$, temperature and the total concentration of copper and cyanide. The concentration of free cuprous is so low that it can be ignored. The equilibrium of copper cyanide complex can be represented by the reactions (1) (3):

$$
\begin{array}{ccc}
C u(C N)-2+C N^{-}=C u(C N) 2-3 & K_{3} & \text { (1) } \\
C u(C N) 2-3+C N^{-}=C u(C N) 3-4 & K_{4} & \text { (2) } \\
H C N=H^{+}+C N^{-} & K_{a}
\end{array}
$$

The respective stability constants of reactions at different temperatures were listed in Table 1 . The $\mathrm{pH}$ value was measured by PHS-3C instrument.

Table 1. Stability constants at different temperatures.

\begin{tabular}{|c|c|c|c|c|}
\hline $\mathrm{T}\left({ }^{\circ} \mathrm{C}\right)$ & 25 & 40 & 50 & 60 \\
\hline $\log \mathrm{K}_{3}$ & 5.3 & 4.91 & 4.67 & 4.45 \\
\hline $\log \mathrm{K}_{4}$ & 1.5 & 1.11 & 0.86 & 0.64 \\
\hline $\log \mathrm{K}_{a}$ & -9.21 & -8.84 & -8.60 & -8.41 \\
\hline
\end{tabular}

The mass balance of the copper and cyanocuprate species can be described by the following equation:

$$
C_{\left[\mathrm{Cu}_{\text {总 }}\right]}=C_{\left[\mathrm{Cu}(\mathrm{CN})_{2}^{-}\right]}+C_{\left[\mathrm{Cu}(\mathrm{CN})_{3}^{2-}\right]}+C_{\left[\mathrm{Cu}(\mathrm{CN})_{4}^{3-}\right]}
$$

By considering reactions (1) (3) and solving the equation of the mass balance, the distribution of copper cyanide species can be calculated.

The cycle voltammetry of copper cyanide solution was detected by electrochemical workstation (Zahner IM6e), the working electrode was titanium coated with iridium and tantalum oxides with an area of $1 \times 1 \mathrm{~cm}^{2}$, cleaned by nitric acid and washed by deionized water. Titanium plate was used as counter electrode and saturated calomel electrode as the reference electrode.

Potentiostatic electrolysis was carried out to define the process of anodic reaction and sodium diethyldithiocarbamate was added at low potential, which could form cupric precipitate on the anode to prove the generation of $\mathrm{Cu}^{2+}$. The phase of anode product was identified by a D/max-2500PC X-ray diffractometer (Japan) with $\mathrm{Cu} \mathrm{K}_{a}$ radiation.

Direct electrowinning was used to recover copper with plexiglass cell at different temperature. The anode was titanium coated with iridium and tantalum oxides, while the titanium plate was cathode. As the constant current electrowinning method was used, the anode potential (vs. SCE) was measured by Agilent 34410A instrument. The current efficiency of cathode was determined by measuring the mass of cathode.

\section{Results and discussion}

\subsection{Distribution of copper cyanide species}

The concentration of $\mathrm{Cu}(\mathrm{CN})-2$ was obtained by the following equation:

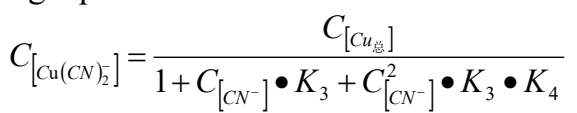

The same method was also used to calculate $\mathrm{Cu}(\mathrm{CN}) 2-3$ and $\mathrm{Cu}(\mathrm{CN}) 3-4$ concentration. The results of distribution showed the $\mathrm{Cu}(\mathrm{CN})-2$ concentration was less than $10^{-5} \mathrm{~mol} / \mathrm{L}$ at $25^{\circ} \mathrm{C}, \mathrm{Cu}(\mathrm{CN}) 2-3$ and $\mathrm{Cu}(\mathrm{CN}) 3$ 4 were dominant in copper cyanide solution at $\mathrm{pH} 12$, copper concentration was $0.125 \mathrm{~mol} / \mathrm{L}$, free cyanide was $0.096 \mathrm{~mol} / \mathrm{L}$.

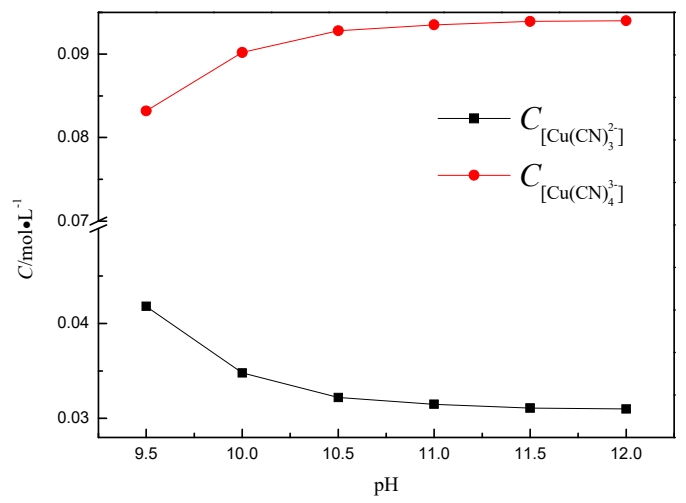

Fig. 1. Distribution of copper cyanides at different $\mathrm{pH}$

Fig. 1 shows the relationship between distribution of copper cyanides and $\mathrm{pH}$ at $25^{\circ} \mathrm{C}$. As can be seen, the $\mathrm{Cu}(\mathrm{CN}) 3-4$ complex ions were the main existence form of copper cyanide complexes in solution, and the proportion of $\mathrm{Cu}(\mathrm{CN}) 3-4$ concentration improved with the $\mathrm{pH}$ increased and tended to be stable when the $\mathrm{pH}$ exceeded 11. The relation of $\mathrm{Cu}(\mathrm{CN}) 2-3$ concentration vs. $\mathrm{pH}$ was contrary to $\mathrm{Cu}(\mathrm{CN}) 3-4$. The distribution of copper cyanide species was depended on the ratio of copper and free cyanide from reaction (5) at certain temperature. Since the dissociation equilibrium of $\mathrm{HCN}$ was affected by $\mathrm{pH}$, the content of free cyanide increased with increasing of $\mathrm{pH}$, which led to more cyanide chelated with copper.

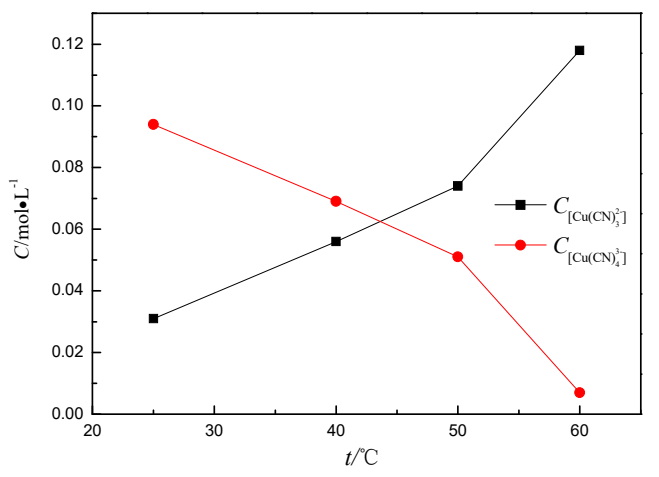

Fig. 2. Distributions of copper cyanides at different temperature 
Fig. 2 shows the distributions of copper cyanide species under different temperature at $\mathrm{pH} 12$. As can be seen, the temperature was a significant factor of the distribution of copper cyanide species, because the stability constants was relate to temperature. The content of $\mathrm{Cu}(\mathrm{CN}) 2-3$ increased with the temperature increasing and $\mathrm{Cu}(\mathrm{CN}) 3-4$ concentration decreased gradually. The $\mathrm{Cu}(\mathrm{CN}) 2-3$ was dominant in the distribution as temperature exceeding $60^{\circ} \mathrm{C}$.

\subsection{Study on the cyclic voltammetry of anode}

Fig. 3 showed the cyclic voltammetry curve of copper cyanide solution at $25{ }^{\circ} \mathrm{C}$ on a platinum anode. The anodic reaction of copper cyanide solution can be divided into three parts. The first region was about $0.35 \sim 0.47 \mathrm{~V}$ (vs. SCE), the precipitate was not found on anode by potentiostatic electrolysis at $0.4 \mathrm{~V}$, the conversion of $\mathrm{Cu}(\mathrm{I}) / \mathrm{Cu}(\mathrm{II})$ was assumed in the region which was proved in subsequent work. The current increased and reached a limiting value, then it decreased with increasing potential from about 0.5 to $0.58 \mathrm{~V}$. The free or complex cyanide was oxidized in the range which led to current increased sharply, and the precipitate was formed on the anode which was the reason of current decay. When the potential exceeded $0.58 \mathrm{~V}$, the current increased with increasing potential, the bubble was observed on the surface of anode. The similar results were obtained in Fig. 4 by titanium coated with iridium and tantalum oxides.

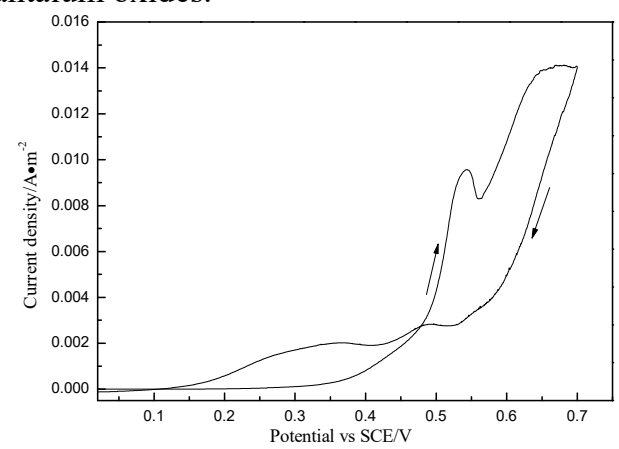

Fig. 3. Cyclic voltammetry curve of copper cyanide solution with $0.15 \mathrm{~mol} / \mathrm{L} \mathrm{Cu}, 0.6 \mathrm{~mol} / \mathrm{L} \mathrm{CN}^{-}, 0.5 \mathrm{~mol} / \mathrm{L} \mathrm{NaOH}$ and 1 $\mathrm{mol} / \mathrm{L} \mathrm{Na}_{2} \mathrm{SO}_{4}$ on a platinum electrode at $25^{\circ} \mathrm{C}$

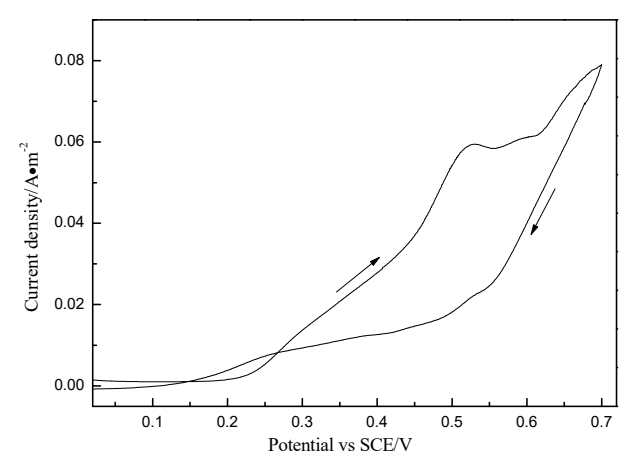

Fig. 4. Cyclic voltammetry curve of copper cyanide solution with $0.15 \mathrm{~mol} / \mathrm{L} \mathrm{Cu}, 0.6 \mathrm{~mol} / \mathrm{L} \mathrm{CN}^{-}, 0.5 \mathrm{~mol} / \mathrm{L} \mathrm{NaOH}$ and 1 $\mathrm{mol} / \mathrm{L} \mathrm{Na}_{2} \mathrm{SO}_{4}$ on coated titanium electrode at $25^{\circ} \mathrm{C}$

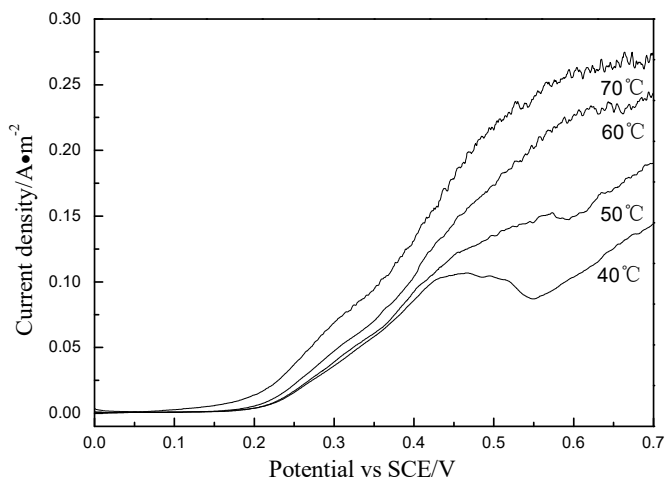

Fig. 5. Ploarization curves of copper cyanide solution with 0.15 $\mathrm{mol} / \mathrm{L} \mathrm{Cu}, 0.6 \mathrm{~mol} / \mathrm{L} \mathrm{CN}-0.5 \mathrm{~mol} / \mathrm{L} \mathrm{NaOH}$ and $1 \mathrm{~mol} / \mathrm{L}$

$\mathrm{Na}_{2} \mathrm{SO}_{4}$ at different temperatures

Polarization measurements were carried out at different temperature, with the results shown in Fig. 5. The current increased with increasing temperature because the $\mathrm{Cu}(\mathrm{CN}) 2-3$ was easier oxidized than $\mathrm{Cu}(\mathrm{CN}) 3-4$ and the distribution of copper cyanide species was changed. The limit current disappeared when the temperature reached $50^{\circ} \mathrm{C}$ however the precipitation still existed on the anode, which showed that the formation of precipitation can been inhibited at a higher temperature but not been avoided.

\subsection{Analysis of anode products}

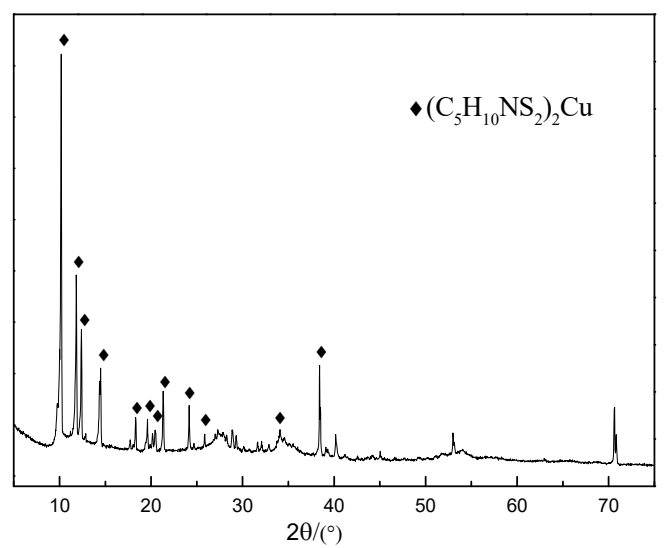

Fig. 6. XRD pattern of anode after electrolysis with adding sodium diethyldithiocarbamate at $0.38 \mathrm{~V}$

Fig. 6 shows the XRD pattern of anodic precipitate after potentiostatic electrolysis. As can be seen, the production of $\mathrm{Cu}^{2+}$ was proved by adding sodium diethyldithiocarbamate at low potential $(0.4 \mathrm{~V})$, which indicated that the reaction of $\mathrm{Cu}^{+}$oxidation occurred. $\mathrm{Cu}(\mathrm{CN}) 3-4$ being supposed predominant, the anode reactions were represented by the follow steps:

$$
\begin{gathered}
\mathrm{Cu}(\mathrm{CN}) 3-4 \rightarrow \mathrm{Cu}^{2+}+4 \mathrm{CN}^{-}+\mathrm{e}^{-} \\
2 \mathrm{Cu}^{2+}+10 \mathrm{CN}^{-} \rightarrow 2 \mathrm{Cu}(\mathrm{CN}) 3-4+(\mathrm{CN})_{2} \\
(\mathrm{CN})_{2}+2 \mathrm{OH}^{-} \rightarrow \mathrm{CNO}^{-}+\mathrm{CN}^{-}+\mathrm{H}_{2} \mathrm{O}
\end{gathered}
$$




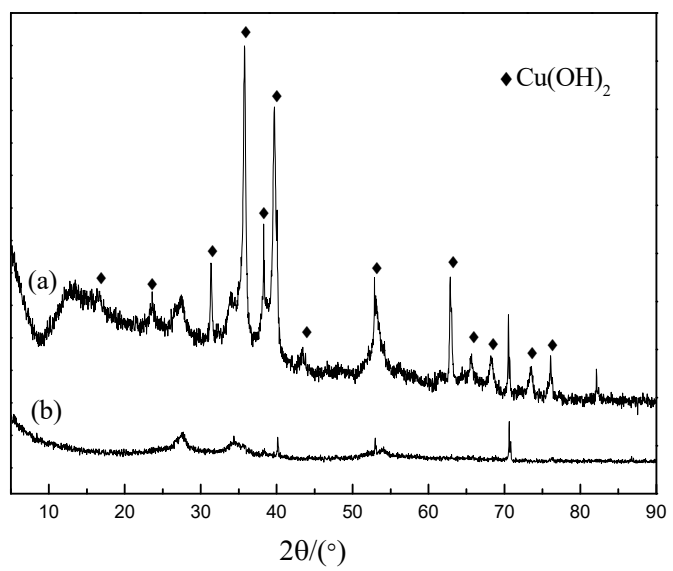

Fig. 7. XRD pattern of anode after electrolysis at $0.5 \mathrm{~V}$ (a) after electrolysis (b) before electrolysis

Fig. 7 showed the XRD pattern of anode after electrolysis at $0.5 \mathrm{~V}$. As can be seen, the precipitation on the anode was cupric hydroxide. When a large number of $\mathrm{Cu}^{2+}$ generated on the anode, there were not enough cyanide to reduce cupric ions on the surface of anode, which led to cupric hydroxide formed. The cupric hydroxide have been proved to catalyze the oxidation of cyanide, the cyanide was oxidized directly on the anode coated $\mathrm{Cu}(\mathrm{OH})_{2}$. Thus, high anodic potential accelerated the oxidation of cyanide to reduce the recovery of cyanide.

\subsection{Copper recovery by electrolysis}

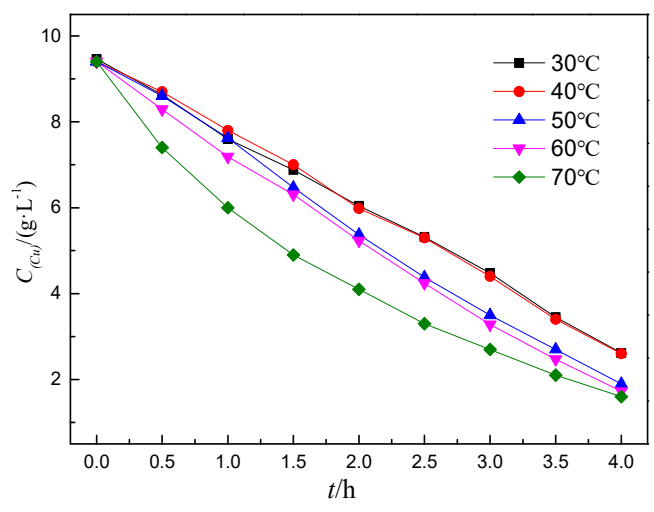

Fig. 8. Copper concentration with time at $100 \mathrm{~A} / \mathrm{m}^{2}$

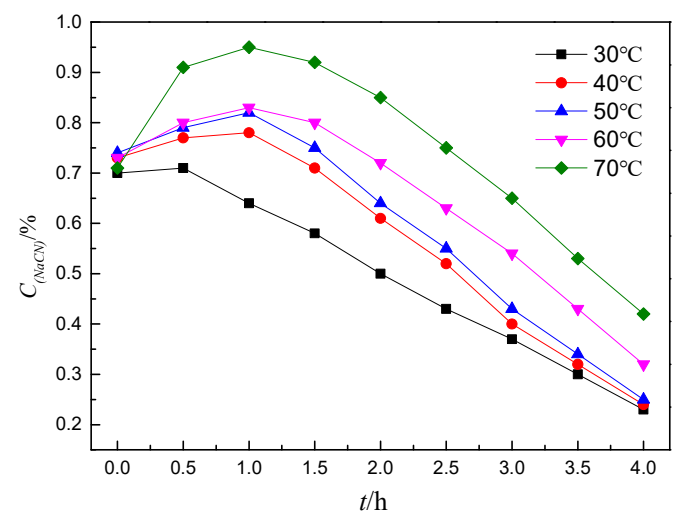

Fig. 9. Free cyanide concentration with time at $100 \mathrm{~A} / \mathrm{m}^{2}$
The concentration-time relationships of copper and cyanide at different temperature were shown in Fig. 8 and Fig. 9 respectively, the anode potential was controlled to less than $0.5 \mathrm{~V}$. The reaction rate of electrodepositon increased slightly at $30 \sim 60^{\circ} \mathrm{C}$ but the rate was accelerated significantly at $70^{\circ} \mathrm{C}$. The final copper concentration decreased with decreasing temperature but there was little difference at $50 \sim 70^{\circ} \mathrm{C}$, the recovery of copper reached $80 \mathrm{wt} \%$. The temperature changed the distribution of copper cyanide species, the $\mathrm{Cu}(\mathrm{CN}) 2-3$ was the main complex ion at $70^{\circ} \mathrm{C}$, the reaction occurred more easily because the deposition potential of $\mathrm{Cu}(\mathrm{CN}) 2-3$ was more lower than $\mathrm{Cu}(\mathrm{CN}) 3-$ 4. Fig.9 showed the change of the free cyanide concentration with time, the effect of temperature was significant. At $70^{\circ} \mathrm{C}$, the concentration of cyanide increased sharply on initial stage because the coppercyanide complex dissociated and free cyanide was released, then decreased further with increase in time. The decrease of current efficiency caused the releasable cyanide couldn't counteract the loss of oxidation on anode, the final value of free cyanide decreased significantly compared to the original concentration, the cyanide wasn't effectively recovered.

\section{Conclusions}

1) The copper cyanide species mainly existed as $\mathrm{Cu}(\mathrm{CN}) 2-3$ and $\mathrm{Cu}(\mathrm{CN}) 3-4$, the latter was usually dominant at normal temperature. The distribution was significantly controlled by temperature and $\mathrm{Cu}(\mathrm{CN}) 2-3$ changed to primary complex at $60^{\circ} \mathrm{C}$.

2) The formation of cupric ion was confirmed by experiment with adding sodium diethyldithiocarbamate at low potential and the cupric ion oxidization was the main cause of the cyanide loss. The precipitate on the anode at high potential was identified as cupric hydroxide.

3) The copper can be recovered effectively by direct electrowinning but the cyanide was damaged.

\section{References}

1. Dai X W, Simons A, Breuer P. Miner. Eng. 25, 1(2012)

2. $\mathrm{Hu} \mathrm{H}$ S, Yang M D, Dang J, Wang J F,. Nonferrous Metals. 52, 61(2000)

3. Gonzales O A, Alonso F N, Salas A U. Miner. Eng. 23, 324(2009)

4. Xie F, Dreisinger D. J Hazard Mater. 169,333(2009)

5. Xie F, Dreisinger D. Trans.Nonferrous Met. Soc. China, 20, 1136(2010)

6. Dutra A J B, Rocha G P, Pombo F R. J Hazard Mater. 152, 648(2008)

7. Lu J M, Dreisinger, Cooper W C. Hydrometallurgy. 64, 1(2002)

8. Lemos F A, Sobral L G S, Dutra A J B. Miner. Eng. 19, 388(2006) 
9. Cheng S C, Gattrell M, Guena T, Macdougall B. Electrochim. Acta. 47, 3245(2002)

10. Wang B X, Lan X Z, Song Y H, Li Y S. Mater. Sci. Forum. 41-47, 610(2009)

11. Wang Q S, Huang B H, Li H D. R J Environ. Sci. 12, 18(1999)

12. Lu J, Dreisinger D B, Copper W C. J. Appl. Electrochem. 32, 1109(2002)

13. Lu J, Dreisinger D B, Copper W C. J. Appl. Electrochem. 32, 1119(2002)

14. Szpyrkowicz L, Kelsall G H, Souto R M, Ricci F, Kaul S N. Chem. Eng. Sci. 60, 523(2005)

15. Lu J, Dreisinger D B, Copper W C. Hydrometallurgy. 66, 23(2002) 